\title{
LOW COST WEB-APPLICATION FOR MANAGEMENT OF 3D DIGITAL BUILDING AND COMPLEX BASED ON BIM AND GIS
}

\author{
S.W. Trisyanti ${ }^{1}$, D. Suwardhi ${ }^{1}$, A. Murtiyoso ${ }^{2}$, P. Grussenmeyer ${ }^{2}$ \\ 1 3D Modelling and Information System, Remote Sensing and GIS Group, Bandung Institute of Technology, Indonesia - \\ shafarina.wahyu@students.itb.ac.id, deni@gd.itb.ac.id \\ ${ }^{2}$ Photogrammetry and Geomatics Group, ICube Laboratory UMR 7357, INSA Strasbourg, France - \\ arnadi.murtiyoso@insa-strasbourg.fr, pierre.grussenmeyer@insa-strasbourg.fr
}

\section{Commission II}

KEY WORDS: 3D CityDB, BIM, Building, GIS, Web-Application

\begin{abstract}
:
Buildings are an important focus that needs to be modeled in three-dimensional (3D) city model. 3D models of buildings can be used to assist the construction and maintenance of cities. Currently there are many technologies that can be used to manage data and information from buildings or cities, such as Geographical Information System (GIS) and Building Information Modeling (BIM). GIS is good for managing data areas or regions, while BIM is good for managing building data and information. GIS and BIM have their respective advantages and disadvantages, so a combination of both is needed to do a good management of building and area data and information. This research will use an open source web-application that can be used for asset and facility management. This web-application can display two-dimensional (2D) GIS and BIM data, but cannot display 3D GIS data yet. The results of surveying and mapping and from existing architectural drawing can build 3D GIS data using 3D City Database (3D CityDB) which is integrated with the web-application used.The purpose of this study is to store building and city data, visualize it in a 3D model, and use it to perform spatial analysis in customized open source web-applications. The study cases for this research are campus area of Institut Teknologi Bandung (ITB), Sayang Village, and Penglipuran Village.
\end{abstract}

\section{INTRODUCTION}

\subsection{Background}

Building is one of the important element for the city development and maintenance. Every building has a process or a life cycle, start from planning, designing, maintaining, and demolishing. The process involves various disciplines, so it needed a thing that can integrate all of these disciplines, such as an application for all the process. One of the processes that can be carried out in the application is management of building facilities. Facilities management encompasses a range of disciplines and services to ensure the functionality, comfort, safety and efficiency of a built environment - buildings and grounds, infrastructure and real estate. Facilities management is divided into two basic areas: Hard Facilities Management (Hard FM) and Soft Facilities Management (Soft FM). Hard FM deals with physical assets such as plumbing, heating and cooling, elevators. Soft FM focuses on tasks performed by people such as custodial services, lease accounting, catering, security, grounds keeping (IBM Corporation, 2018).

To manage data and information from a building or city, many technologies have been used for a long time, such as Geographical Information System (GIS) and Building Information Modeling (BIM). Geographical Information System (GIS) is an information system designed to work with data that refers to spatial or geographic coordinates. GIS is a database system with special capabilities for spatial reference data, as well as a set of operations to work with that data (Zhang, et.al., 2009). According to David William Rhind, GIS can be described as "a hardware, software, and procedure system designed to support the collection, management, manipulation, analysis, modeling, and display of spatial data references to solve complex planning and management problems". In processing it requires two kinds of data, namely spatial data obtained from mapping results and non-spatial data obtained from attributes through surveys.

Building Information Modeling (BIM) is a system, works in 3D models, through intelligent databases that contain information about decision making design, accurate construction document production, prediction of performance factors, cost estimation and scenario design, and construction planning (Yuan and Zizhang, 2008). BIM keeps realistic 3-dimensional representation of buildings or other structural elements that show architectural elements and building structures. For development plans, BIM can be made based on plan drawings / Detail Engineering Design Drawing (DED) which is then made 3D by making drawings according to its height. As for existing buildings, which have already been built, BIM can be made by drawing measured images / As Built Drawing or by conducting surveys if there are no measurable drawings.

In the use of BIM, not everything can be facilitated, such as spatial analysis that requires data to have the same coordinate system, both local and georeferenced. BIM only uses local coordinates that vary from one object to another, so it cannot be used to analyze a number of things, for example tracing cables and plumbing between buildings, searching routes between rooms and buildings and spatial analysis relating to lighting systems, noise pollution, and rainwater infiltration. Because of these deficiencies, it is necessary to combine BIM with a GIS that can complement it.

Nowadays, there're some application of asset and facility management, but commercial and relatively expensive. In this paper, one of the open source application for asset and facility 
managemet, CMDBuild. CMDBuild is an open source web enterprise environment, to configure custom applications for asset management. CMDBuild allows the management of assets database, like assets and business resources, equipment leased to customers, technological infrastructure and systems. It has native mechanisms to model the database, to design workflow, to configure reports and dashboards, to build connectors with external systems, to geo-refer assets, and to administer the system (Tecnoteca, 2015).

CMDBuild can be customized according to the needs of the object to be managed, including building facility management. There is a custom CMDBuild for Property \& Facility Management, openMAINT. OpenMAINT is a tool for the management of buildings, installations, mobile asset and related logistical, economic and maintenance activities. It allows the client to keep under control the situation of assets, knowing at all times the composition, dislocation, functional relations, rules for updating over time, and managing the complete life-cycle. OpenMAINT can manage the mobile assets (machineries, technical elements, furniture, ect.), real estate (buildings, infrastructures, etc.) and the related maintenance activities (planned and in case of breakdown) and also logistical and economic ones. OpenMAINT is a ready-to-use application, configured with all the essential basic storages, processes, reports and dashboards (Tecnoteca, openMaint-CMDBuild, 2015). CMDBuild already has a facility to display GIS 2D and BIM data. But for asset and facility management 3D GIS data is needed so that building floor data does not overlap. Because the data piled up will complicate vertical spatial analysis, for example for utilities such as plumbing, electricity lines, and vertical circulation paths.

\subsection{Related Works}

Other research have been studied about the 3D building or area modeling, such as the 3D modeling of heritage building, Liao Family Temple, China (Xu et al., 2014). In that research, the acquisition method were using photogrammetry and laser scanner. Then the modelling process is using manual method and saved as BIM data. For the 3D area modeling, there's a research about 3D documentation of heritage complexes using photogrammetry and laser scanner techniques (Murtiyoso et al., 2018). The 3D model generated in that research divided into 4 scales from large complex until detail element of building. The 3D model generated in this research and the virtual reality can be used for management of the heritage site.

The visualization of 3D modeling are in GIS or BIM or the integration of them. Some of researches have been done for visualize the 3D model, such as Geospatial Database for Heritage Building Conservation (Basir et al., 2014). On that research, they used GIS for 3D modeling to make the database usefull for spatial analysis. 3D modeling process was used manually using SketchUp and the the model converted to GIS format. The 3D model can be visualized on ArcScene and have a good database for heritage building which usefull for conservation. The other research is Information Management for Cultural Heritage Conservation (Radin and Zivkovic, 2013). On this research, the information management for specific museum documentation using ARTEMIS, the development of documentation system for all activities in the field of cultural heritage conservation in Serbia. The documents are in different file format, includes the 3D without any spatial analysis. It's only give the information of objects.

\subsection{Objectives}

The purpose of this study is to store building and city data, visualize it in a $3 \mathrm{D}$ model, and use it to perform spatial analysis in customized open source web-applications. The building and city data will be stored in different data model, BIM and GIS.

\section{MATERIALS AND METHODS}

\subsection{Case Study}

The case studies for this research are campus area of Institut Teknologi Bandung (ITB), West Java, Indonesia and two villages in West Java and Bali.

2.1.1 Institut Teknologi Bandung (ITB): ITB is a multicampus that has several locations, at Ganesa (Bandung), Jatinangor (Sumedang), and Cirebon. The first location and most popular campus is ITB-Ganesa. It has some heritage building and mixed with semi-modern and modern building, same as the buildings on campus ITB-Jatinangor. As the multicampus, all of the asset and facility on ITB should be manage in good ways. The ITB current data for asset and facility management have been saved in a database, but didn't have good relation with the real objects.

2.1.2 Villages: Some villages as the case studies on this research such as Sayang Village and Penglipuran Village. Sayang Village is located at Jatinangor, Sumedang, West Java and it's a mix function village that have area for education (campus), industry, and trades. Penglipuran Village is located at Bali, and it's a cultural village that have a traditional houses and own culture. Both of villages didn't have enough digital database that can be used for manage some village data, such as village economy potential data, village population data, and property ownership data.

\subsection{Methods}

3D models of buildings and areas in this study were built from the results of survey and mapping and also using existing architectural drawing data. The data acquisition from survey and mapping is using photogrammetric and laser scanner techniques. The photogrammetry techniques used in this research are UAV photogrammetry and terrestrial Close Range Photogrammetry (CRP). UAV Photogrammetry used to map the whole areas and CRP used to map the individual buildings. The laser scanning used in this research are Terrestrial Laser Scanner (TLS) and handheld laser scanner. Handheld laser scanner can be used to map the interior of buildings if the buildings didn't have enough architectural drawing data. The example for architectural drawing data shown in Figure 1, as the floor plan of Library at ITB-Jatinangor. The exterior of that building then mapped using drone photogrammetry.

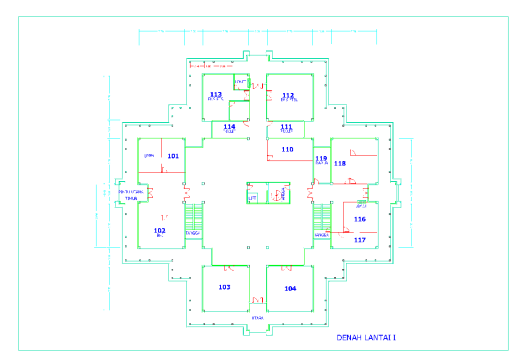

Figure 1. Floor plan for Library building at ITB-Jatinangor 
The architectural drawing data and resullt of survey and mapping then modeled into 3D building model using 3D modeling software. The 3D building model saved as BIM data that includes all of the detail building information as semantic data. The 3D model saved as Industrial Foundation Classes (IFC), the data structure for BIM. And the result of survey and mapping for area then modeled into 3D model as GIS data which can be used to do spatial analysis. 3D GIS data will be built using 3D City Database (3D CityDB) which will be integrated into the CMDBuild application. 3D CityDB is a free geo database to store, represent, and manage virtual 3D city models on top of a standard spatial relational database. The database schema implements the City Geography Markup Language (CityGML) standard with semantically rich and multi-scale urban objects facilitating complex analysis tasks, far beyond visualization. CityGML is an open data model and XML-based data exchange format describing the most relevant urban and landscape objects along with their spatial and nonspatial attributes, relations, and their complex hierarchical structures in five levels of detail.

The 3D model as BIM and 3D GIS then visualized in the CMDBuild. For the ITB campus model, OpenMAINT customization can be used for asset and facility management. But for the village model, the CMDBuild with own customization was used because there's no suitable customization for village database than can be used.

\section{RESULTS AND DISCUSSION}

\subsection{D Building Model}

From the survey and mapping method, the drone photogrammetry can generated the point cloud of building and elevation model of area. One result for the building in ITB Jatinangor is the dense cloud of Library building (Figure 2). From the dense cloud, the 3D building model exterior then created by manual digitazing using 3D modelling software (Figure 3). And the interior of building is modelling using the architectural drawing data and dense cloud from laser scanner technique. The developed 3D building model has information as the semantic data, such as building materials, room area value, room volume value, and. room height. The $3 \mathrm{D}$ model saved as IFC structure data on BIM model.

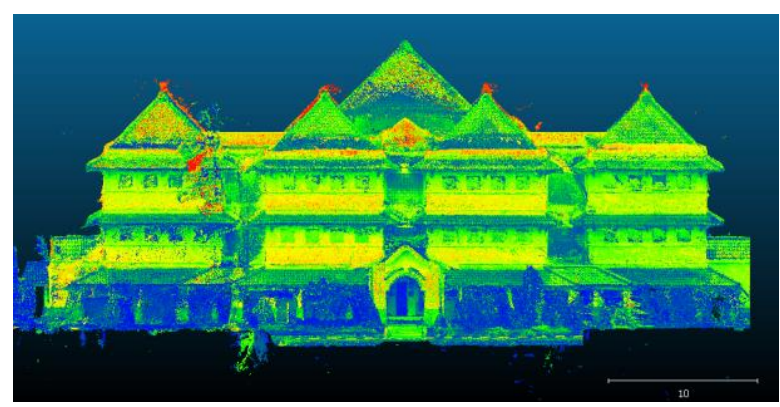

Figure 2. Library of ITB Jatinangor dense cloud

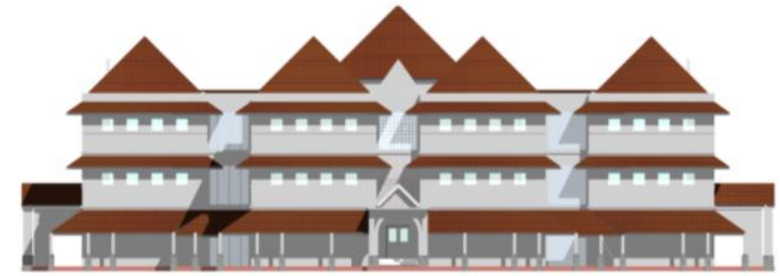

Figure 3. 3D Model of ITB-Jatinangor library

\subsection{D Map}

Besides point cloud for building exterior, the aerial photogrammetry (UAV or drone) generated the elevation model of area. Using manual digitization, the form of the building mass with the roof form and height can also be generated. It was modeled as 3D model with Level of Detail (LoD) 2 or 3. The 3D model LoD 2 only show the mass of building with height. The 3D model LoD 3 can show the roof geometry and height of building. The 3D map then saved as 3D GIS (

Figure 4) which can be usefull for spatial analysis.

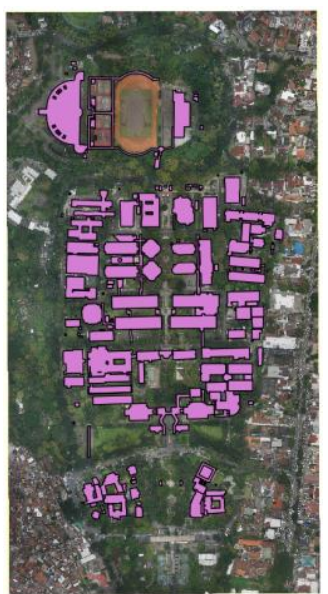

(a)

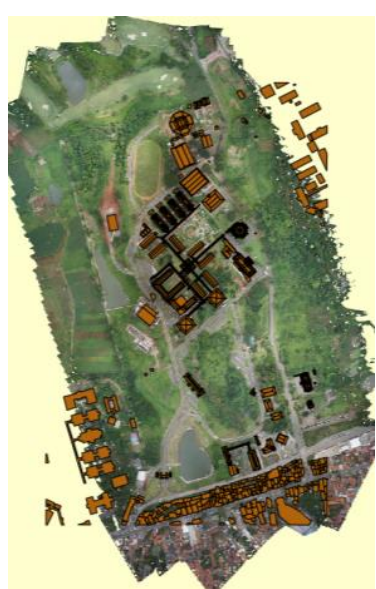

(b)
Figure 4. 3D model LoD 2/3 of campus ITB (a) Ganesa and (b) Jatinangor

\subsection{Web-Application}

CMDBuild can determine the data to be accessed based on the user who accesses it. In this study, users are divided into two, namely public users and private users. The visualization for public and private user are different based on the needs of their use. Public users need to access stored data and only need general information with their visualizations (Figure 5). The public access can see the location of building, room, parking area, and other facility. Besides that, the user can also see the panoramic photo that can make them easily knowing the room. 


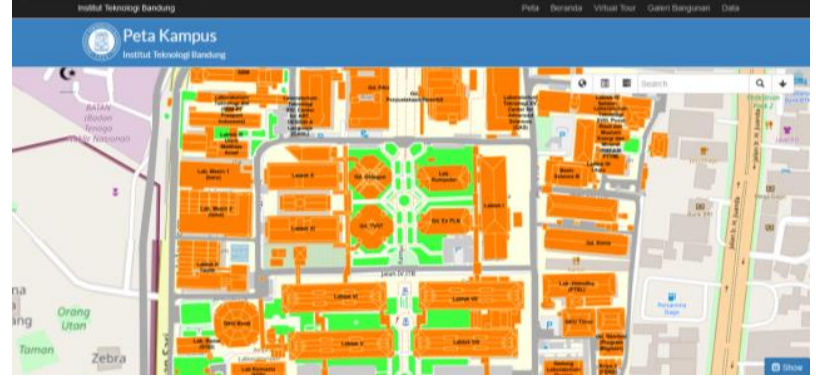

(a)

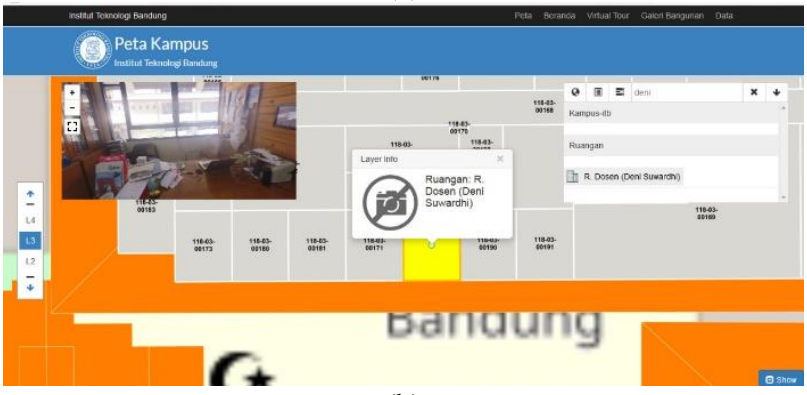

(b)

Figure 5. Web for public user: (a) 2D Map and (b) floor plan on each building with panoramic image for each room

Private users are users who can access the data stored and can be managed by that data, the campus data can be seen in Figure 6 and the village data can be seen in Figure 7. This user can add, delete, and edit data. All of those action will be saved as history data. User can also customized this application based on their needs. For example, on 3D map user can visualized the relation of village population data with property ownership data. User of CMDBuild can be freely customized it because it is only an empty container. OpenMAINT customization is used for building model (BIM). With this customization, user can see all of the semantic data as IFC class. The IFC class and data on it can be edited in the 3D modeling software.

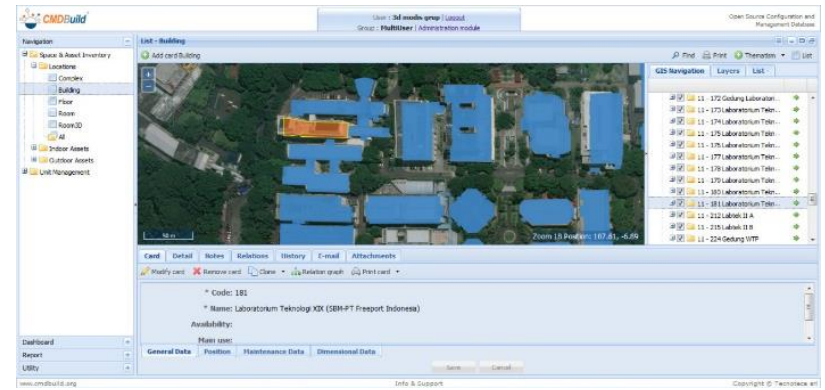

(a)

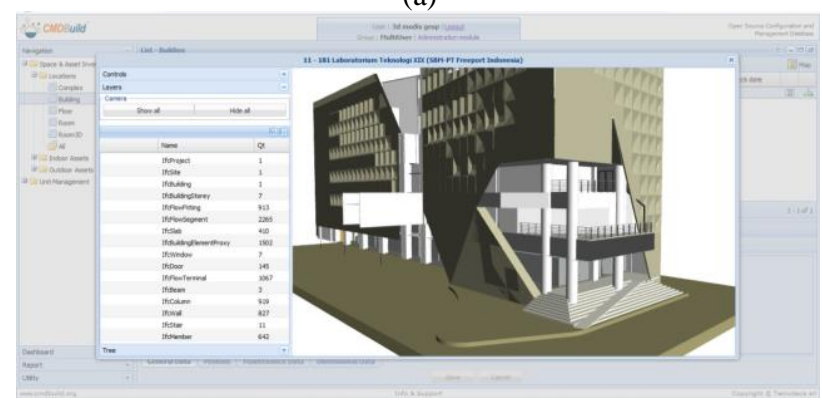

(b)

Figure 6. CMDBuild for private user visualization of ITB: (a) 3D map (GIS) and (b) 3D model of each building (BIM)

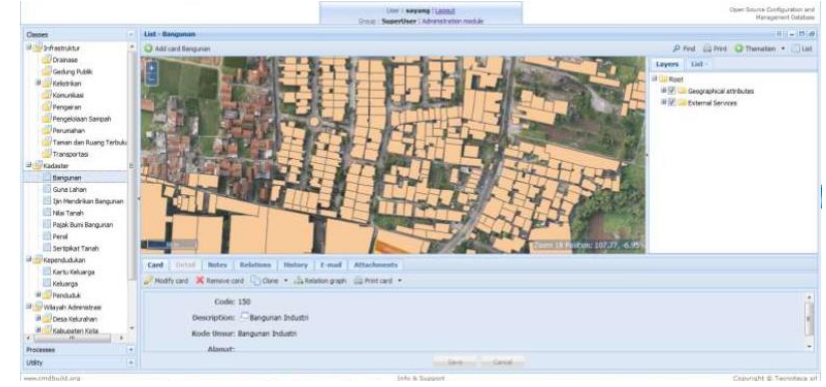

Figure 7. CMD Build for private user of village map

\section{CONCLUSION}

Based on the research that have been done, the conclusion from this research are:

1. 3D model of building and area can be created from architectural drawing data combine with surveying and mapping techniques. It can built the 3D model of area (LoD $2 / 3$ ) and detail building includes interior ( $\operatorname{LoD} 4)$.

2. 3D model of building and area are saved in the different model data depend on the needs of analysis. The 3D building model is saved as BIM data and 3D area model as GIS data. Both of them can be integration for visualized on the web-based application.

3. CMDBuild as open source web-application can be useful for asset and facility management for buillding using BIM data. But for the area, the GIS data that can be visualize in CMDBuild is only 2D GIS, 3D GIS not yet available. It can make the spatial analysis can't be work for 3D model.

4. Free customization of CMDBuild is very usefull for user based on the database required.

\section{REFERENCES}

Basir, W.N.F.W.A., Setan, H., Majid, Z., Chong, A., 2014. Geospatial Database for Heritage Building Conservation. $8^{\text {th }}$ Internatonal Symposium of the Digital Earth (ISDE8). IOP Conf. Series: Earth and Environmental Science 18

IBM Corporation. (2018, December 20). What is facilities management? | IBM. Retrieved from IBM:

https://www.ibm.com/topics/facilities-management

Murtiyoso, A., Grussenmeyer, P., Suwardhi, D., Awalludin, R., 2018. Multi-Scale and Multi-Sensor 3D Documentation of Heritage Complexes in Urban Areas. ISPRS International Journal of Geo-Information.

Radin, M., Zivkovic, V., 2013. Information Management for Cultural Heritage Conservation.

Tecnoteca. (2015, September 14). CMDBuild. Retrieved from CMDBuild: http://www.cmdbuild.org/en/prodotti/cmdbuild

Tecnoteca. (2015, September 22). openMaint-CMDBuild. Retrieved from CMDBuild:

http://www.cmdbuild.org/en/prodotti/openmaint

Yuan, L., Zizhang, HE., 2008. 3D Indoor Navigation: a Framework of Combining BIM with 3D GIS. 44th ISOCARP Congress 2008 
The International Archives of the Photogrammetry, Remote Sensing and Spatial Information Sciences, Volume XLII-2/W17, 2019

6th International Workshop LowCost 3D - Sensors, Algorithms, Applications, 2-3 December 2019, Strasbourg, France

Zhang, X., Arayici, Y., Wu, S., Abbott, C., Aouad, G., 2009.

Integrating BIM and GIS for Large Scale (Building) Asset

Management; A Critical Review. Paper for CC2009 